\title{
El Prólogo de Cromwell y el juego interlocutivo de la recepción teatral
}

CROMWELl'S PROLOGUE AND THE INTERLOCUTORY GAME OF THEATRICAL RECEPTION

Amon Paul Ndri*

* Universidad Alassane OuattaraBouaké, Costa de Marfil

Correo-e: amonpaul.dri@gmail.com Recibido: 13 de abril de 2018

Aprobado: 14 de septiembre de 2018
Resumen: Con base en los postulados de Victor Hugo y Lope de Vega, se analiza el carácter lúdico del teatro, arte espectacular que vincula el texto dramático con el lector/espectador, lo que da paso a una vivencia colectiva. En el caso del drama moderno, se propone que el escritor se sitúe al margen de posicionamientos doctrinales propios de las normas academicistas. Finalmente, se hace hincapié en la necesidad de ejercer una crítica objetiva alejada de ideologías, a fin de que el público pueda acercarse al teatro del mejor modo posible.

Palabras clave: creación artística; artes escénicas; teatro contemporáneo; dramaturgo; crítica de arte

Abstract: On the basis of Victor Hugo's and Lope de Vega's postulates, the ludic nature of theater is analyzed; spectacular art that links dramatic texts to the reader/spectator, which makes room for a collective experience. In the case of modern drama, the writer is proposed to place aside their own doctrinal stances of academicism. Finally, the need to exercise objective criticism far from ideologies is stressed so that the public can appreciate theater as best as possible.

Keywords: artistic creation; performing arts; contemporary theatre; playwrights; art criticism 


\section{INTRODUCCIÓN}

El célebre "Prefacio" de Cromwell, obra de Victor Hugo, ofrece interesantes apuntes teóricos para el estudio del teatro. Por su naturaleza, este arte no puede desvincularse del espectáculo, lo cual lo convierte en un género destinado al dictamen popular. El drama tiene la finalidad de ofrecer plena satisfacción al público, ávido de nuevas sensaciones. Por este motivo, el autor francés pone el acento sobre la recepción, que implica "la búsqueda de la liberación de la lengua, de la renovación del vocabulario y la emancipación del verso" (Fernández Chapo, 2005-2006: 57). Lo relevante es la capacidad seductora de la palabra, su poder evocador, que se materializa mediante la propuesta dramática y por cuya mediación se alcanza el disfrute colectivo.

Según Victor Hugo, el acto de escritura teatral no es más que un juego que preside la creación dramática. En su articulación concreta, tiene una naturaleza inconformista, por cuanto niega el patrocinio exterior de las instancias normativas. Esta postura iconoclasta conduce necesariamente al antiacademicismo que repele los dogmas de inspiración aristotélica. Con ello, el teatro emprende un camino novedoso muy lejos de lo reglamentario y posibilita diferentes senderos para la libertad de creación.

Se trata, en efecto, de un enfoque acorde con nuevos patrones en torno a los cuales gravitan la "unión de lo grotesco a lo sublime, el alma con el cuerpo, la tragedia con la comedia" ${ }^{1}$ (71). De esta forma, Victor Hugo consigue aunar polos opuestos. Así, se vislumbra el empeño de concretar "un pensamiento metateatral" para conseguir un arte total (Fernández Chapo, 2005-2006: 60). A la postre, uno de los objetivos del drama será dar cuenta de la dimensión dualista del hombre, compuesto de lo carnal y lo etéreo (18). En suma,

1 Todas las citas pertenecientes al "Prólogo" de Cromwell, corresponden a Hugo, 1963, por lo cual sólo se anota el número de página. estamos ante un teatro sui generis que se fundamenta en:

\begin{abstract}
la realidad de los hechos, sobre todo la de las costumbres y la de los caracteres, restaura lo que han truncado los analistas, armoniza lo que han desollado, adivina sus omisiones y las separa, llena sus lagunas con imaginaciones que tengan color de época, agrupa lo que han dejado disperso, restablece el juego de los hilos de la providencia sobre las marionetas humanas, reviste al todo de una forma poética y natural a la vez, y le da esa vida de verdad y de originalidad que engendra la ilusión, ese prestigio de realidad que apasiona al espectador, y al poeta en primer lugar, pues el poeta obra de buena fe. De modo que el fin del arte es casi divino: resucitar, si hace historia; crear, si hace poesía (52).
\end{abstract}

Dicho enfoque epistemológico inaugura horizontes mentales que contrastan con el rigorismo clásico, contrario a la espontaneidad propia del escritor. El juego es un componente lúdico que participa en la creación y sirve de catalizador para la inspiración, sobre todo en lo concerniente a las palabras, materia prima al alcance del artista. Éstas no son meras herramientas, más bien constituyen auténticos soportes didácticos al servicio de "la forma óptica del pensamiento" (57). Las palabras, esto es, el armazón textual, son para el dramaturgo lo que los ladrillos para el albañil. Constituyen resortes básicos que le permiten al poeta superarse para alcanzar el máximo grado estético. La creación poética nace de la capacidad transformadora del artista, que se vale de la materia prima para alimentar sus propósitos. Lo anterior termina por convertirse en un juego del que resulta difícil sustraerse.

Según los argumentos de Victor Hugo, el arte dramático sirve como "punto de partida desde donde elevarse hacia lo bello con una percepción más fresca y estimulada" (26). El público completa el binomio juego/recepción que configura 
definitivamente la práctica teatral. El objetivo de este artículo es poner de relieve la ambivalencia conceptual del juego, que afecta tanto a la escritura dramática como a la actuación. En palabras del escritor francés:

He aquí, pues, una nueva religión, una sociedad nueva; sobre esta doble base, es menester que veamos crecer una poesía nueva. Hasta entonces, obrando en ello como el politeísmo y la filosofía antigua, la musa puramente épica de los antiguos sólo había estudiado la naturaleza desde un aspecto, expulsando del arte, sin compasión, casi todo lo que, en el mundo sometido a su imitación, no se correspondía con un cierto tipo de belleza. Tipo magnífico en principio; pero, como sucede siempre a lo que es sistemático, convertido en los últimos tiempos en falso, mezquino y convencional. El cristianismo introdujo la verdad en la poesía. Como él, la musa moderna verá las cosas con mirada más elevada, y más amplia. Se dará cuenta de que, en la creación, no todo es humanamente 'bello', que la fealdad existe al lado de la belleza, lo deforme junto a lo gracioso, lo grotesco en el reverso de lo sublime, el mal con el bien, la sombra con la luz $(21,22)$.

Cuando Victor Hugo habla de una nueva religión, en realidad se sitúa en una dimensión antropocéntrica de corte renacentista, que otorga al ser humano la capacidad reguladora de su propia existencia. Se trata de la fe en los valores intrínsecos de la persona, llamada a conquistar el mundo mediante las leyes cartesianas. El poeta no obedece a otro dios que no sea el de su propia inspiración. De ahí la proyección utópica de una sociedad nueva, su nacimiento sobre las ruinas de lo viejo.

Precisamente por eso, el drama moderno ostenta su insumisión al poder fáctico de las coerciones doctrinales, que entorpecen el crecimiento del drama y su búsqueda de derroteros. Para que el teatro sea una poesía total debe situarse lejos del mimetismo servil, consistente en la imitación infecunda de los cánones erigidos. Según Victor Hugo, "hay dos especies de modelos: aquellos que se han hecho según las reglas y, antes de ellos, aquellos según los cuales se han hecho las reglas" (46). Ni unos ni otros son compatibles con el drama moderno, en tanto su objetivo es la ilusión que crea expectativa en el receptor.

El teatro es praxis y la escena constituye el lugar predilecto donde se confunden - en el sentido de fundir con- la forma y el fondo, el juego y la vivencia colectiva, para alcanzar la apoteosis catártica. En consecuencia, el juego dramático entronca con la función apelativa inherente a la recepción como respuesta concreta del espectador a la propuesta que tiene delante. De ahí la relación de interdependencia entre la escena y el público, que hace de la función teatral un juego de interlocución. Esto supone la existencia de dos instancias que interactúan: la literatura dramática y el lector; la escena y el espectador, las cuales consiguen generar una dinámica interpretativa. En definitiva, el teatro tiene la ventaja de ofrecer un espectáculo que suscita una dimensión colectiva. Para ello, el poeta ha de crear las condiciones necesarias que implementen la alteridad y despierten en el espectador los referentes culturales latentes en la obra.

Conviene puntualizar que las ideas vertidas en el "Prefacio" de Cromwell no son totalmente nuevas. Fue Lope de Vega quien se opuso inicialmente a la regla de las tres unidades aristotélicas. Antes de sentenciar que cuando escribe encierra "los preceptos con seis llaves" (Vega, 1971: 133), formula que: "lo trágico y lo cómico mezclado, / y Terencio con Séneca, aunque sea / como otro Minotauro de Pasife, / Harán grave una parte, otra ridícula, / que aquesta variedad deleita mucho; / buen ejemplo nos da naturaleza, / que por tal variedad tiene belleza (141). Así lo reconoció el propio Victor Hugo con una actitud de honestidad intelectual que lo dignifica.

Antes de la publicación de Cromwell, en 1820, el novelista italiano Manzoni se sumó a la voz 
díscola de Lope de Vega al preconizar la superación estética del angosto marco de las unidades de tiempo y espacio. El propio Stendhal no quiso quedarse atrás al percatarse de la ausencia de las tragedias 'nacionales' en las producciones dramáticas y subrayó la necesidad imperiosa de implementar las vivencias antropológicas de los pueblos. En 1813, con la publicación de Alemania, Madame de Staël asestó la estocada definitiva al viejo teatro al criticar abiertamente la devoción de los franceses por la tragedia clásica. A continuación, propuso un nuevo drama con mayor verdad histórica, que fuera más verosímil por la mezcla de lo cómico y lo trágico.

En cualquier caso, el mérito de Victor Hugo radica en haber sabido captar y capitalizar el debate en torno a la demanda de un marco doctrinal acorde con los nuevos tiempos.

\section{DEL JUEGO DRAMÁTICO A LA RECEPCIÓN CRíTICA}

El teatro es un espejo lacaniano (Lacan, 1966: 94) que refleja su doble, en tanto el juego inicial del escritor gesta a su vez el actoral que mediatiza la semiótica artística. Esta simetría plantea una doble vertiente: el lector-receptor y el actorpúblico. En otros términos, la lectura del texto dramático es un cuerpo a cuerpo que se asemeja al abrazo erótico de los amantes. La obra escrita es "una máquina perezosa que exige del lector un arduo trabajo cooperativo" (Eco, 1993: 39). Entre el texto y su recepción impera una relación intimista que conduce a la representación mental que el lector hace de la pieza. Leer una obra dramática consiste en buscar los signos no verbales que se oponen "a la literatura, al teatro de texto, a los medios escritos, a los diálogos e incluso, a veces, a la narrativa" (Pavis, 1998: 434). Es decir, se trata de aprehender el esplendor de la teatralidad, que: es el teatro menos el texto, es una espesura de signos y de sensaciones que se edifica sobre el escenario a partir del argumento escrito, es una especie de percepción ecuménica de los artificios sensuales, gestos, tonos, distancias, sustancias, luces, que sumerge al texto bajo la plenitud de su lenguaje exterior (Barthes, 1964: 41-42).

El lector se convierte en un diletante al transformar los materiales didascálicos en una puesta en escena imaginaria, lo que constituye una experiencia lúdica. La lectura dramática le permite al sujeto-lector entablar una relación privilegiada con el objeto-estético para hacerse una idea de su representación. Por ende, se crean las condiciones psicológicas de la escenificación anticipada de la obra. En palabras de Ubersfeld, se trata de "leer el teatro" (1977: 8). El lector individual prefigura la implicación colectiva de los espectadores en un ejercicio de coparticipación.

Asistir a la puesta en escena supone "el análisis de los procesos mentales, intelectuales y emocionales de la comprensión del espectáculo" (Pavis, 1998: 382-383). El teatro es el arte del espectador (Brecht, 1954), orientado hacia "las estructuras mentales y sociológicas del público y su papel en la constitución del sentido" (Pavis, 1998: 383). Los mecanismos metateatrales, sensoriales y performánticos puestos al servicio de la actuación suscitan en la psique colectiva un juego que aspira a ser una fiesta. Sólo de este modo se crea un lenguaje metateatral que provoca una compenetración entre los involucrados.

Desde esta perspectiva, Ángel Berenguer pone especial "énfasis en el concepto de espectáculo teatral antes que en los aspectos literarios del texto. El hecho dramático aparece considerado aquí como un fenómeno esencialmente espectacular" (1998: IX). De acuerdo con los escritos de César Oliva Olivares y Francisco Torres Monreal sobre las "fiestas dionisias o dionisiacas" (1997: 27), podemos afirmar que: 
la représentation théâtrale met en mouvement des croyances, des passions qui répondent aux pulsions dont est animée la vie des groupes et des sociétés. L’art atteint ici à ce dégré de généralité qui déborde le cadre de la littérature écrite; l'esthétique y devient action (Duvignaud, 1973: 12). ${ }^{2}$

El teatro tiene una dimensión social, ya que es el espectador el que acude a las butacas para presenciar las representaciones. Como lo demuestra Arthur Miller, un público "es una comunidad de la cual cada miembro lleva en sí lo que estima, como su angustia o su esperanza o su problema personal; que le aparta de los demás" (Duvignaud, 1973: 13). No es de extrañar que el profesor Manuel Pérez Jiménez defina al receptor-crítico del siguiente modo:

miembro de un grupo social cuya configuración ideológica se manifiesta [...] La crítica adquiere así una dimensión colectiva que la convierte en indicio del sector de mentalidad de la que el crítico participa y su resultado patentiza la reacción del grupo social ante el acto comunicativo constituido por la obra (1998: 16).

En relación con lo anterior, después de la Revolución francesa, y muy concretamente tras la conclusión de la Segunda Guerra Mundial, todos los géneros y formas de manifestación artística experimentaron una profunda mutación:

Musique, peinture, cinéma revendiquent des modes d'expression qui leur sont propres. La poésie contemporaine explore des domaines qui ne possèdent plus rien de «poétique» au regard des critères admis, le théâtre moderne repousse les situations théâtrales héritées

2 "La representación teatral pone en movimiento creencias y pasiones que responden a los impulsos que animan la vida de los grupos y las sociedades. El arte llega aquí a este grado de generalidad que va más allá del marco de la literatura escrita; la estética se convierte en acción” (la traducción es mía). d'une longue tradition et se forge un langage dramatique nouveau (Goldenstein, 1989: 7). ${ }^{3}$

Esos últimos intentos tuvieron como particularidad considerar al espectador un elemento transcendente en la valoración de la obra teatral para "restablecer una dialéctica en la transacción entre producción y recepción” (Pavis, 1985: 233).

A juicio de César Oliva Olivares, el teatro:

es un medio de comunicación artística, por el cual el escenario se convierte en significante de un general significado, cuyo proceso de significación descodifica el espectador mediante un pacto táctico que establece con el citado emisor, esto es, el escenario. El teatro, así visto, es un proceso de comunicación sui generis, similar a todos los artísticos en donde la respuesta del receptor no puede ser de idéntica naturaleza a la del emisor (1979: 41).

Artaud (1971) concibe la puesta en escena como una especie de explosión de sentidos. De acuerdo con Ángel Berenguer, se debe considerar la idea de que, en el teatro, el juego de interlocución genera "una reacción del público que lo recibe" (1991: 53). Del oficio de los actores se desprende un intento de alcanzar la quintaesencia de la obra. Desde esta perspectiva, el histrión es un receptor también, que actúa en su calidad de experto y basa su juego "en la experiencia o en el conocimiento del teatro, su intrahistoria y sus relaciones con el arte y la sociedad de su tiempo" (Berenguer, 1991: 53). Esta postura privilegiada lo diferencia del mero espectador consumidor.

3 "La música, la pintura, el cine reivindican sus propios modos de expresión. La poesía contemporánea explora áreas que ya no tienen nada "poético" en términos de los criterios aceptados, el teatro moderno rechaza las situaciones teatrales heredadas de una larga tradición y está forjando un nuevo lenguaje dramático" (la traducción es mía). 
Del JUEGO ESCÉNICO A LA CRíTICA TEATRAL

Si la obra motiva el espectáculo, podemos decir sin lugar a dudas que la escena gesta su propia crítica. Para Manuel Pérez, la crítica teatral se divide en dos grupos: la inmediata o de prensa, y la mediata o de investigación. La primera:

se define como la práctica que, suscitada por una contemplación directa del espectáculo teatral, resulta elaborada, con ocasión del mismo, a través de textos publicados en medios de comunicación [...] tales como periódicos y revistas, bien sean éstas especializadas o no (Pérez, 1998: 8).

En cuanto a la segunda:

abarca un campo tan ingente como fecundo en el que ocupa un lugar relevante la desarrollada en el ámbito universitario. En ella es posible reconocer, sin esfuerzo notable, unas connotaciones de prestigio, a veces respaldadas por una larga tradición, a las que no son ajenas ni su capacidad de profundización en el análisis de las obras ni la eficacia con la que genera productos notablemente más elaborados y contundentes que los de la crítica inmediata (Pérez, 1998: 4).

Tanto la crítica inmediata como la de investigación llevan a cabo una misma misión notable: la explicación de la escena. De este proceso, resulta que la crítica ofrece "una mayor comprensión del fenómeno teatral en su conjunto y de la obra en particular a la sociedad" (Giella, 1994: 42). En este sentido, Mikel Dufrenne asegura:

la fantasmatique est plutôt ce qui anime l'œuvre que ce que l'œuvre suscite chez le récepteur; et d'autre part, si subjectif qu'il soit, le fantasme procède d'un certain rapport au monde, et l'image fantasmatique n'est pas totalement illusoire: elle n'est pas seulement le représentant de la pulsion, elle représente aussi le monde où la pulsion trouve son objet (1976: 53). ${ }^{4}$

La actividad crítica "contempla la actualización escénica de unos textos concebidos, precisamente, por y para la escena” (Pérez, 1994: 211). De este modo, debería estar capacitada para aclarar y aproximar al lector el universo de la obra. Como receptor, el crítico:

peut nous communiquer son expérience de lecteur. Peu importe que cette expérience soit personnelle [...] Pour rendre justice à l'œuvre, il suffit que le critique dise ce qu'elle lui inspire. Car une œuvre n'est inspirée que parce qu'elle est elle-même inspirante [...] La réflexion sur l'œuvre qui privilégie et développe un sens n'est pas une trahison, puisque l'œuvre... en s'incarnant dans le lecteur, s'objective et s'ouvre à une histoire ; chaque lecture la maintient dans cette histoire où son sens ne cesse de s'enrichir. Plus exactement, chaque lecture découvre partiellement la richesse de ce sens. Ainsi la critique ne s'ajoute pas à l'œuvre mais il ajoute l'œuvre à elle-même (Dufrenne, 1967: 155). ${ }^{5}$

Jean Paul Sartre lo explica en términos que ofrecen una mirada nueva sobre la crítica:

4 "la fantasía es más bien lo que inspira la obra que lo que la obra provoca en el receptor. Por otra parte, por más subjetiva que sea, la fantasía arranca desde una determinada relación con el mundo, y la imagen fantasmática no es totalmente ilusoria: no es sólo el representante de la pulsión, sino representa también el mundo donde la pulsión se realiza" (la traducción es mía).

5 peut nous communiquer son expérience de lecteur. Peu importe que cette expérience soit personnelle [...] Pour rendre justice à l'œuvre, il suffit que le critique dise ce qu'elle lui inspire. Car une œuvre n'est inspirée que parce qu'elle est elle-même inspirante [...] La réflexion sur l'œuvre qui privilégie et développe un sens n'est pas une trahison, puisque l'œuvre...en s'incarnant dans le lecteur, s'objective et s'ouvre à une histoire ; chaque lecture la maintient dans cette histoire où son sens ne cesse de s'enrichir. Plus exactement, chaque lecture découvre partiellement la richesse de ce sens. Ainsi la critique ne s'ajoute pas à l'œuvre mais il ajoute l'œuvre à elle-même (Dufrenne, 1967: 155) 
L'écrivain ne s'adresse pas à une postérité douteuse, il est une liberté qui entend communiquer avec d'autres libertés pour les convoquer à une entreprise commune; il peut éveiller en l'homme un regard nouveau sur le monde pour l'appeler à se sentir engagé, à prendre conscience de sa responsabilité, à travailler à la libération de l'homme en tous les hommes (Dufrenne, 1967: 155). ${ }^{6}$

De ello se deriva que valorar una obra consiste en apostar por la deconstrucción/construcción de la misma. Este binomio se adentra en la función explicativa de la crítica, la cual desempeña un importantísimo papel en la comprensión del teatro. De un modo especial, Esslin explicita que la misión primigenia del crítico consiste en desentrañar el texto:

No sabemos muy bien lo que una obra, una novela, puede implicar y por eso, precisamente, existen los críticos. Por eso están ahí, para intentar ver, comprender, lo que ha intentado decir el autor o, por lo menos, lo que ha dicho sin querer (1984: 117).

Al ser un arte práctico por excelencia, la puesta en escena contemporánea no puede escaparse del juicio de los expertos. Según Manuel Pérez, "la actividad crítica aparece como un proceso inserto en la instancia de la recepción teatral y, por ello, estrechamente relacionada con ésta" (1998: 12). Todos los preceptos o criterios que antes referimos deberían sustentar el análisis de la obra dramática, pero en ocasiones resulta difícil separar esta actividad de las ideologías imperantes.

Según las investigaciones de Lucien Goldmann sobre las visiones del mundo o sectores de

6 "El escritor no se dirige a una posteridad dudosa, es una libertad que piensa comunicarse con otras libertades con el fin de convocarlas a un cometido compartido: puede despertar en el hombre una nueva mirada hacia el mundo para llamarlo a comprometerse, a ser consciente de su responsabilidad, a obrar por la liberación de todos los hombres" (la traducción es mía). mentalidad, los actos individuales no son inocentes y dependen más bien del grupo social al que pertenece el sujeto. La ideología se plasma a través del medio de comunicación en el que el individuo se inscribe (Goldmann, 1959: 24). En consecuencia, el crítico se convierte en el portavoz de su clase social. De esta manera, sus juicios adquieren una relevancia transindividual. La crítica es inversa a la creación teatral, en el sentido de que va del plano conceptual al universo imaginario. En este punto, conviene plantear la oportunidad de hacer un juicio a esta actividad. Las derivas mercantilistas son las hendiduras por las que se filtra, en ocasiones, el escollo ideológico que empaña la crítica:

Ahora bien, es posible observar a lo largo de la historia del arte, y del teatro en particular, momentos en que la crítica se enfrentó a callejones sin salida. Sin embargo, estas aporías - en tanto efecto de lectura, por lo que podría decirse que son extrínsecas al objetono permanecieron inmutables, sino que el discurso sufrió reubicaciones, expandiendo sus propias fronteras epistemológicas. Una de estas instancias fueron las vanguardias históricas, que pusieron a prueba los mismos límites de lo que se consideraba arte. En el campo teatral, desde los escandalosos estrenos de Alfred Jarry, pasando por Antonin Artaud hasta llegar a Samuel Beckett, los ejemplos son abundantes. 'Absurdo', 'non-sens', fueron algunas de las etiquetas para incluir - con no pocas resistencias- a tales producciones en la grilla del arte teatral (López, 2007: 3).

Las consideraciones críticas han de ser de naturaleza objetiva para ayudar al entendimiento de la obra y no confundirse con la censura y la invectiva. En cualquier caso, deben permanecer al margen de las ideologías y de todo tipo de interferencias. Al respecto, la teórica Beatriz Liliana López afirma: 
La crítica se mueve bajo la impronta del deseo taxonómico (movimiento clasificatorio), una herencia del positivismo y del cientificismo; rotular el objeto implica, de algún modo, una dominación sobre el mismo. Las estéticas canónicas y las divisiones genéricas aún siguen siendo un punto de referencia, que suele deshacerse frente al fenómeno teatral, lo que se traduce en la utilización frecuente del prefijo 'neo' adjuntado al anclaje de lo ya conocido. Así, 'neorrealismo', 'neonaturalismo', o 'neocostumbrismo', se alternan con el uso del 'hiper' en casos donde se sospecha que un género o una estética ha sido llevada a sus límites (2007: 6).

Bajo este prisma, la necesidad de hacer una crítica de críticas debe tenerse muy en cuenta. Desde el punto de vista teórico, analizar una puesta en escena es un juego que ha de saber centrarse en los límites amparados por la objetividad. Al margen de las implicaciones ideológicas, el crítico teatral no debe tener otro propósito que el de expandir el sentido de la obra propuesta. Su cometido debe ser meramente estético. Hacer una revisión de las críticas teatrales nos ayuda a tener presente que éstas deben situarse lejos de las convicciones de quien las enuncia.

\section{CONCLUSión}

Al plantear el nexo dialéctico existente entre el texto dramático y la escena, Victor Hugo nos recuerda permanentemente la función social del teatro. Este arte del espectáculo no puede menospreciar la relación que lo mantiene ligado al público, sin el cual pierde su categoría de popular. Tal y como sostenemos, el juego es un componente que hace del teatro un género particular. Desde el punto de vista conceptual, presenta un carácter ambivalente, por cuanto afecta doblemente a la propia actividad creativa y a la recepción. El juego impulsa una nueva mirada crítica sobre el género íntimamente relacionada con el espectador. La alteridad es una las condiciones necesarias para que se lleve a cabo:

Por lo tanto, será en esta representación, en la decodificación por parte del público de sus códigos lingüístico, paralingüístico y kinésico y en la interpretación ideológica de su código icónico y sonoro, en donde deberemos buscar la verdad o mentira de esta pretendida proyección social (Forgas Berdet, 1990: 72).

Esta dualidad del texto dramático constituye la esencia del teatro, que no ha de obviarse para cualquier análisis de este tipo de obras. La presencia obligada del público es de por sí un motivo suficiente para que el poeta tome muy en serio un planteamiento estético de los temas a tratar. No es un asunto baladí, y el mismo Lope de Vega insiste en su importancia. El teatro es praxis y, desde este postulado, la actuación constituye una mediación necesaria para la plasmación definitiva del juego colectivo. El trance grupal es la constancia de que el arte dramático permite experimentar un tipo particular de goce. Por lo tanto, existe una retroalimentación permanente entre el texto escrito y la representación, entre la escena y la recepción. Este dato es importante para un acercamiento al teatro, arte social por antonomasia inscrito en un contexto que remite, por necesidad, a vivencias culturales:

Chaque époque à son propre système de genres, qui est en rapport avec l'idéologie dominante. Une société choisit et codifie les actes qui correspondent au plus près à son idéologie; c'est pourquoi l'existence de certains genres dans une société, leur absence dans une autre, sont révélatrices de cette idéologie (Todorov, Tzvetan en Corvin, 1994: 4). ${ }^{7}$

7 "Cada época alberga su propio sistema de géneros, que, a su vez, está relacionado con la ideología dominante. Una sociedad elige y codifica los actos que más se corresponden con su ideología; Es por eso que la existencia de ciertos géneros en una sociedad, su ausencia en otra, son reveladoras de esta ideología" (la traducción es mía). 
El drama romántico toma en cuenta la complejidad del hombre y todas sus contradicciones. Por eso, Artaud apuesta por un teatro exigente y cruel que propicie la simbiosis creativa entre el espectador y los actores.

En definitiva, tanto Lope de Vega como Victor Hugo delinean con precisión la imperiosa necesidad de establecer unas correctas coordenadas entre el espectáculo y el espectador. La doble dimensión del teatro implica que la escena propicia ingentes posibilidades interpretativas. Sin embargo, el análisis del juego escénico puede trasladarse a un ámbito meramente elitista. Así, pasamos del arte popular a categorías respaldadas por los centros universitarios y la prensa que vienen en apoyo del juego estético para iluminarlo. Por eso, deben cuidarse las opiniones vertidas en las columnas, para no desvirtuar el importante cometido de la crítica teatral. Las universidades han de formar expertos llamados a situarse lejos de las ideologías, que analicen objetivamente la relación dialéctica existente entre la escena y la recepción.

\section{REFERENCIAS}

Artaud, Antonin (1971), El teatro y su doble, Buenos Aires, Editorial Sudamericana.

Barthes, Roland (1964), Essais critiques, París, Editions Du Seuil.

Berenguer, Ángel (1991), Teoría y crítica del teatro: Estudios sobre teoría y crítica teatral, Alcalá de Henares, Universidad de Alcalá.

Berenguer, Ángel (1998), "Prólogo”, en Manuel Pérez Jiménez, El teatro de la transición politica (1975-1982): recepción, crítica y edición, Kassel, Edición Reichenberger.

Brecht, Bertolt (1954), Petit Organon pour le théâtre, París, L'arche.

Corvin, Michel (1994), Lire la comédie, París, Dunod.

Dufrenne, Mikel (1967), Esthétique et philosophie, t. 1, París, Klincksieck.

Dufrenne, Mikel (1976), Esthétique et philosophie, t. 2, París, Klincksieck.

Duvignaud, Jean (1973), Sociologie du théâtre. Essai sur les ombres collectives, París, Presses Universitaires de France.

Eco, Umberto (1993), Lector in fabula. La cooperación en el texto narrativo, Barcelona, Lumen.

Esslin, Martin (1984), "Entrevista de Eugène Ionesco", en Ángel Berenguer, Teatro europeo de los años 80, Barcelona, Laia.
Fernández Chapo, Gabriel (2005-2006), "El pensamiento metateatral de Victor Hugo", en Hologramática Literaria, vol. 1, núm. 1, pp. 47-64.

Forgas Berdet, Esther (1990), "Ideología y recepción teatral. «Lo social» en el teatro de Joaquín Dicenta", Anales de Filología Hispánica, vol. 5, pp. 71-84.

Giella, Miguel Ángel (1994), De dramaturgos: teatro latinoamericano actual, Buenos Aires, Corregidor.

Goldenstein, Jean-Pierre (1989), Pour lire le roman, Louvain-laNeuve, Duculot.

Goldmann, Lucien (1959), Le dieu caché, París, Gallimard.

Hugo, Victor (1963), "Prefacio", en Cromwell, Buenos Aires, Huemul.

Lacan, Jacques (1966), Ecrits, París, Éditions du Seuil.

López, Beatriz Liliana (2007), "Territorios baldíos de la crítica teatral", Territorio Teatral, núm. 1, pp. 1-14, disponible en: http://territorioteatral.org.ar/html.2/articulos/pdf/05.pdf

Oliva, César y Torres Monreal, Francisco (1997), Historia básica del arte escénico, Madrid, Catédra.

Oliva Olivares, César (1979), "Lectura semiológica de Así que pasen cinco años", Primer Acto. Cuadernos de Investigación Teatral, núm. 182, pp. 40-43.

Pavis, Patrice (1985), Voix et images de la scène (Vers une sémiologie de la réception), Villeneuve d'Ascq, Presses Universitaires de Lille.

Pavis, Patrice (1998), Diccionario del teatro. Dramaturgia, estética, semiología, Barcelona, Paidós.

Pérez, Manuel (1994), "La didáctica del teatro a través de los textos: hacia el concepto de edición escénica”, Teatro. Revista de Estudios Teatrales, núm. 5, pp. 179-228.

Pérez, Manuel (1998), El teatro de la transición política (19751982): recepción, crítica y edición, Kassel, Edición Reichenberger.

Ubersfeld, Anne (1977), Lire le théâtre, París, Éditions sociales.

Vega, Lope de (1971), Arte nuevo de hacer comedia en este tiempo, Madrid, Cátedra.

Amon Paul Ndri. Doctor en Filología Hispánica por la Universidad de Alcalá (UAH), España. Profesor Maître-Assistant de Literatura Española en la Universidad Alassane Ouattara-Bouaké, Costa de Marfil. Entre sus últimas publicaciones se encuentran: "Del epónimo toponímico a la proyección de la conciencia preservadora en Fuenteovejuna de Lope de Vega" (Argus-a Artes $\mathcal{F}$ Humanidades, 2017); "Significantes intermediales y estructura significativa en La casa de Bernarda Alba, de Federico García Lorca" (Telón de Fondo. Revista de Teoría y Crítica Teatral, 2016); y "Utopocracia Post. Escatología y realidad utópica de la República del Post-teatro" (Argus-a Artes $\mathcal{E}$ Humanidades, 2016). 